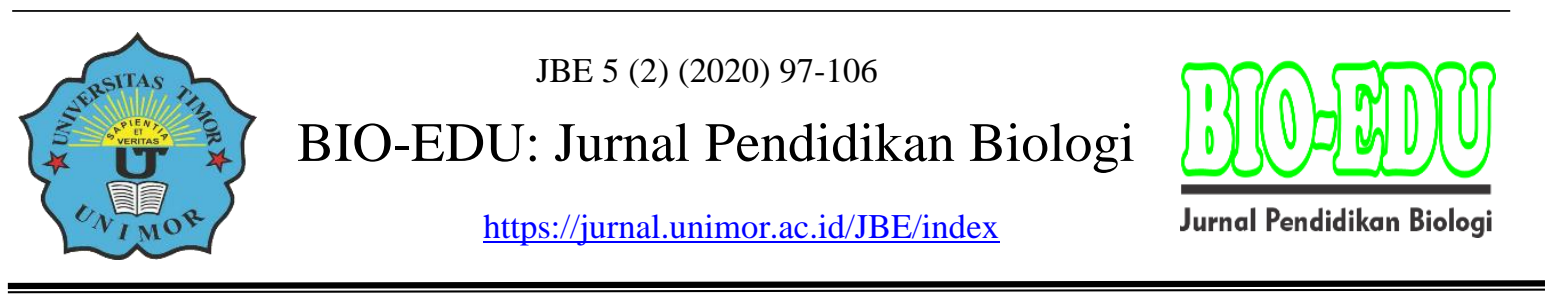

\title{
Pengembangan Modul Pembelajaran IPA Berbasis Etnosains Materi Pencemaran Lingkungan Untuk Melatih Literasi Sains Siswa Kelas VII di SMP
}

\author{
Iis Mardianti ${ }^{1}$, Kasmantoni ${ }^{2}$, Ahmad Walid ${ }^{3}$ \\ Program Studi Ilmu Pengetahuan Alam, Jurusan Sains dan Sosial, Fakultas Tarbiyah \\ dan Tadris, Institut Agama Islam Negeri Bengkulu, Indonesia \\ Email: iismardianti10@gmail.com
}

DOI: $\underline{\text { https://doi.org/10.32938/jbe.v5i2.545 }}$

\begin{abstract}
Abstrak
Tujuan penelitian ini adalah untuk mengembangkan modul pembelajaran IPA berbasis etnosains yang memiliki kelayakan untuk dipakai setelah divalidasi. Metode penelitian menggunakan model pengembangan Borg \& Gall yang terdiri dari 8 tahap yaitu tahap studi pendahuluan, tahap merencanakan penelitian, tahap pengembangan desain, tahap uji lapangan terbatas, tahap revisi hasil uji tahap lapangan terbatas, tahap uji coba secara luas, tahap revisi hasil uji coba lapangan lebih luas, dan tahap produk akhir. penelitian ini dibatasi pada tahap develop yaitu kelayakan modul. Instrument yang digunakan adalah angket untuk kelayakan modul. Subjek penelitian adalah 3 dosen institut agama islam yang terdiri atas 1 dosen ahli bahasa, 1 dosen ahli materi, dan 1 dosen ahli media. Data hasil analisis angket dengan menghitung persentase pencapaian pada setiap komponen persentase pencapaian kriteria kelayakan modul pembelajaran IPA berbasis etnosains yang dikembangkan layak untuk digunakan dengan persentase 88\%, 77,5\%, 87,5\% (kategori sangat layak, layak, dan sangat layak). Dari hasil data tersebut dapat disimpulkan bahwa modul telah layak digunakan sebagai bahan ajar dalam menunjang proses belajar mengajar pada materi pencemaran lingkungan.
\end{abstract}

Kata kunci : "Pencemaran lingkungan; Etnosains; Modul; Kelayakan”.

\begin{abstract}
The purpose of this study is to develop ethnics-based science learning modules that have the feasibility to be used after validation. The research method uses the Borg \& Gall development model which consists of 8 stages, namely a preliminary study stage, a research planning stage, a design development stage, a limited field test stage, a revised stage of the results of a limited field test stage, a broad trial phase, a revised stage of trial results wider field, and the final product stage. This research is limited to the develop stage, which is module eligibility. The instrument used was a questionnaire for module eligibility. The research subjects were 3 lecturers of Islamic religious institutes consisting of 1 language expert lecturer, 1 material expert lecturer, and 1 media expert lecturer. The results of the questionnaire analysis data by calculating the percentage of achievement in each component of the percentage of achievement of the feasibility criteria of the science learning module based on ethnoscience that was developed is suitable for use with a percentage of $88 \%, 77.5 \%, 87.5 \%$ (the category is very feasible, feasible, and very feasible) . From the results of these data it can be concluded that the module is feasible to be used as teaching material in supporting the teaching and learning process on environmental pollution material.
\end{abstract}

Keywords: "Environmental pollution; Ethnoscience; Module; Feasibility”. 


\section{PENDAHULUAN}

Pendidikan adalah suatu proses dalam rangka mempengaruhi peserta didik supaya mampu menyesuaikan diri sebaik mungkin dengan lingkungannya, dan dengan demikian akan menimbulkan perubahan dalam dirinya (Hamalik, 2011). Berbagai upaya telah dilakukan oleh pemerintah untuk mengubah sistem pendidikan di Indonesia untuk menghadapi abad 21. Salah satu nya adalah perubahan kurikulum pembelajaran (Mukminan, 2014). Hal tersebut tercantum dalam UU No. 20 Tahun 2003 pasal 1 ayat (1) tentang Sistem Pendidikan Nasional (Fokusindo, 2012). Pembelajaran IPA di sekolah diharapkan menjadi lebih menyenangkan bagi siswa dan melibatkan siswa secara aktif melalui Kurikulum 2013 (Ulfah, 2019). Kurikulum 2013 proses pembelajarannya menekankan pada pemberian pengalaman langsung untuk mengembangkan kompetensi agar peduli, menelaah, dan memahami alam sekitar secara ilmiah (Kemendikbud, 2013).

Pesatnya perkembangan Ilmu Pengetahuan dan Teknologi (IPTEK) menyebabkan keterbukaan perdagangan barang, jasa, investasi, modal, dan tenaga kerja (Erman, 2014). Dengan demikian semakin banyak pekerjaan yang menuntut penguasaan keterampilan tingkat tinggi, memerlukan seseorang yang mampu belajar, bernalar, berpikir kreatif, membuat keputusan, dan memecahkan masalah (Widodo, 2014). Kemampuan yang menjadi suatu kebutuhan dan keharusan bagi setiap orang untuk menghadapi tantangan jaman dan kondisi dunia yang dipenuhi dengan produk-produk ilmiah adalah literasi sains (Widodo, 2014). Literasi sains penting untuk menghadapi pertanyaan dalam kehidupan yang memerlukan cara berpikir ilmiah (Anjarsari, 2014). Literasi sains didefinisikan sebagai ilmu pengetahuan dan pemahaman mengenai konsep dan proses sains (Zuriyani, 2012). Organization for Economic Co-operation and Development (OECD 2013) mengemukakan tiga komponen yang terlibat dalam literasi sains. Literasi sains siswa dapat dilatihkan melalui suatu bahan ajar (Permanasari, 2011). Kemampuan literasi sains juga dapat dilatihkan dengan menerapkan pembelajaran yang memanfaatkan lingkungan sosial dan budaya (etnosains) dalam kehidupan sehari-hari sebagai sumber belajar. K13 yang mendukung pembelajaran untuk memanfaatkan budaya terhadap perkembangan ilmu pengetahuan, budaya, teknologi dan seni yang dapat membangun rasa ingin tahu dan kemampuan perseta didik untuk memanfaatkan secara tepat (Cristian, 2017).

Salah satu cara yang dapat dilakukan untuk meningkatkan kualitas proses pembelajaran adalah dengan mempergunakan aspek budaya lokal dalam pembelajaran (Arfinawati, 2016). Etnosains merupakan kegiatan mentransformasikan antara sains asli masyarakat dengan sains ilmiah (Rahayu, 2015). Penerapan pembelajaran sains dengan pendekatan etnosains memerlukan kemampuan guru dalam mengabungkan antara pengetahuan asli dengan pengetahuan ilmiah (Novitasari, 2017). Pembelajaran Ilmu Pengetahuan Alam (IPA) terpadu yang memadukan konsep fisika, kimia, dan biologi lebih berpotensi dalam mengembangkan pengalaman dan kompetensi peserta didik memahami alam sekitar (Listyawati, 2012). Pendidikan IPA (sains) juga dapat dikembangkan dengan bertumpu pada keunikan dan keunggulan suatu daerah, termasuk budaya dan teknologi yang berdasar pada kearifan local (tradisional) (Kartono et al., 2010). Kearifan lokal merupakan ciri khas suatu daerah atau wilayah tertentu yang memiliki nilai kebudayaan, berkembang dalam lingkup local dari generasi ke generasi berikutnya (Toharudin, 2017). Kearifan lokal atau local wisdom dapat dipahami sebagai pengetahuan asli yang berasal dari nilai luhur tradisi budaya (Sibarani, 2013). Oleh karena itu di sekolah perlu ada pelajaran yang memuat materi berbasis kearifan lokal untuk 
mencegah hilangnya kearifan lokal suatu daerah (Kasa, 2011: 3). Etnosains merupakan strategi penciptaan lingkungan belajar dengan mengintegrasikan budaya sebagai bagian dari proses pembelajaran IPA sehingga berguna bagi kehidupannya (Suastra et al., 2011).

Sains asli ini dapat diperoleh peserta didik dari orang tua, tetangga, nenek, kakek, ataupun tokoh-tokoh masyarakat lain. Sementara, sains ilmiah peserta didik dapat memperolehnya dari materi pelajaran yang mereka pelajari di sekolah (Yasin, 2009). Pembelajaran berpendekatan Etnosains menurut Pannen dalam (Sardjiyo, 2005) salah satu caranya adalah mengkaitkan ilmu pengetahuan yang akan dipelajari dengan budaya dimana siswa berasal. Menurut (Sayakti, 2003) menyatakan bahwa pentingnya pembelajaran menggunakan pendekatan budaya lokal dan lingkungan sekitar sebagai sumber belajar supaya proses belajar lebih bermakna bagi siswa. Penelitian (Emdin, 2011) menunjukkan bahwa menghubungkan antara sains dan budaya dapat mempengaruhi peningkatan hasil akademik peserta didik. Hasil penelitian (Rahayu et al., 2006) tentang efektivitas pembelajaran berbasis budaya lokal memberikan hasil yang lebih baik karena pembelajaran berlangsung lebih bermakna bagi siswa. Pembelajaran berpendekatan etnosains lebih menekankan tercapainya pemahaman yang terpadu dari pada sekedar pemahaman mendalam (Krajcik et al., 1999). Salah satu dimensi dalam mempelajari sains adalah pembelajaran sains dimaksudkan untuk memperoleh suatu hubungan antara ilmu pengetahuan dengan teknologi dan masyarakat (Chiapetta \& Koballa, 2010). Pembelajaran adalah suatu proses interaksi antara siswa dengan lingkungan sehingga dapat menyebabkan terjadinya perubahan sikap dan perilaku menuju arah yang lebih baik (Winarni, 2013). Salah-satu komponen dalam proses belajar mengajar tersebut adalah bahan ajar. Bahan ajar yang digunakan tersebut dapat menentukan pencapaian tujuan pembelajaran (Syahid, 2018). Pembelajaran IPA dengan menggunakan bahan ajar berbasis etnosains akan membuat peserta didik lebih tertarik dan antusias terhadap pembelajaran (Damayanti, 2017).

Berdasarkan hasil wawancara Berdasarkan hasil wawancara peneliti dengan Guru Biologi SMP N 20 Kota Bengkulu, terdapat beberapa kendala di antaranya guru dalam proses pembelajaran, penggunaan buku yang hanya terpaku pada buku paket yang tebal dan disediakan oleh pihak sekolah. Keadaan ini membuat proses pembelajaran menjadi tidak seimbang, karena cenderung mengabaikan ranah keterampilan dan afektif. Berdasarkan uraian diatas, penulis merasa perlu melakukan penelitian tentang bahan ajar berupa modul IPA. Modul bercirikan etnosains ini betujuan untuk meningkatkan pemahaman siswa terhadap materi IPA. Mengatasi permasalahan di atas, penulis bermaksud melakukan penelitian pengembangan modul bercirikan pembelajaran etnosains yang berjudul "Pengembangan Modul Pembelajaran IPA Berbasis Etnosains Materi Pencemaran Lingkungan Untuk Melatih Literasi Sains Siswa". Pencemaran lingkungan adalah masuknya atau di masukkannya makhluk hidup, zat, energi, dan/ atau komponen lain ke dalam lingkungan manusia. (Purwanto, 2017). Pencemaran yang di akibatkan oleh faktor kegiatannya sendiri seperti limbah rumah tangga, industri, zat- zat kimia berbahaya, tumpahan minyak, dan lain-lain (Widodo, 2016). Pendekatan etnosains merupakan strategi belajar dengan pengalaman belajar yang mengintergrasikan budaya sebagai bagian dari proses pembelajaran. Menurut (Ogawa, 2007) menyatakan bahwa setiap budaya memiliki ilmu pengetahuan dan ilmu pengetahuan berada di dalam budaya yang dapat disebut sains asli. Oleh karena itu perlu adanya perangkat pembelajaran yang berbasis lingkungan sekitar tempat tinggal siswa yang biasa disebut dengan etnosains. Menurut (Atmojo, 2012) dalam pembelajaran menggunakan pendekatan etnosains siswa 
akan terlibat aktif dalam pembelajaran sehingga akan memiliki pemahaman yang lebih baik dari pada pembelajaran konvensional. Pembelajaran menggunakan buku ajar berbasis etnosains dapat meningkatkan kemampuan pengetahuan sains serta dapat melatih literasi sains siswa (Arfianawati, 2016) yang menyatakan bahwa penerapan pembelajaran berbasis etnosains dapat meningkatkan literasi sains siswa dengan presentase kenaikan sebesar 17\%. Hasil penelitian tersebut juga sejalan dengan pendapat dari (Rosyidah, 2013) yang menyatakan bahwa melalui buku ajar yang berbasis etnosains, diharapkan dapat melatih literasi sains siswa dalam mengkaitkan materi dengan kebudayaan atau kebaiasaan suatu daerah sekitar. Dengan demikian perlu adanya bahan ajar dalam bentuk modul dalam proses pembelajaran IPA berbasis etnosains. Modul adalah bahan ajar yang dirancang secara sistematis berdasarkan kurikulum tertentu dan dikemas dalam bentuk satuan pembelajaran terkecil dan memungkinkan dipelajari secara mandiri dalam satuan waktu tertentu agar siswa menguasai kompetensi yang diajarkan (Darmiyatun, 2013).

\section{METODOLOGI}

\section{Jenis dan Prosedur Penelitian}

Penelitian ini merupakan jenis penelitian pengembangan (research and development). Pengertian penelitian pengembangan menurut Borg \& Gall adalah suatu proses yang di pakai untuk mengembangkan dan memvalidasi produk pendidikan. Penelitian ini mengikuti suatu langkah- langkah secara siklus (Setyosari. 2013).

Model pengembangan yang digunakan mengacu pada model pengembangan Borg \& Gall yang terdiri dari 8 tahap yaitu tahap studi pendahuluan, tahap merencanakan penelitian, tahap pengembangan desain, tahap uji lapangan terbatas, tahap revisi hasil uji tahap lapangan terbatas, tahap uji coba secara luas, tahap revisi hasil uji coba lapangan lebih luas, dan tahap produk akhir.

\section{Studi Pendahuluan (Research and Information Collecting)}

Langkah studi pendahuluan(research and information collecting) ini meliputi analisis kebutuhan, studi pustaka, studi literatur, dan penelitian skala kecil yang di lakukan.

\section{Merencanakan Penelitian}

Setelah melakukan studi pendahuluan, langkah kedua yaitu merencanakan penelitian. Perencanaan penelitian R \& D meliputi : 1) merumuskan tujuan penelitian, 2) memperkirakan tenaga, dana, dan waktu, 3) merumuskan kualifikasi peneliti dan bentukbentuk dalam penelitian.

\section{Pengembangan Desain (Develop Preliminary Of Product)}

Yaitu mengembangkan untuk permulaan dari produk yang akan di hasilkan. Termasuk dalam langkah ini adalah persiapan komponen pendukung, mentiapkan buku pedoman dan petunjuk, dan melakukan evaluasi terhadap kelayakan produk. Langkah pengembangan desain ini meliputi: 1) menentukan desain produk yang akan dikembangkan, 2) menentukan sarana dan prasarana penelitian yang dibutuhkan selama proses penelitian dan pengembangan. 3) menentukan tahap- tahap pelaksanaan uji desain di lapangan. 4) menentukan pihak yang terlibat dalam penelitian.

\section{Uji lapangan terbatas (Preliminary Field Testing)}

Langkah ini merupakan model atau desain berdasarkan uji lapangan terbatas. penyempurnaan produk awal akan dilakukan setelah dilakukan uji coba lapangan terbatas. 


\section{Revisi Hasil Uji lapangan terbatas (Main Product Revision)}

Yaitu melakukan perbaikan terhadap produk awal yang dihasilkan berdasarkan hasil uji coba awal. Perbaikan ini sangat mugkin dilakukan lebih dari satu kali, sesuai dengan hasil yang ditunjukkan dalam uji coba terbatas, sehingga di peroleh draf produk utama yang siap diuji coba lebih luas.

\section{Uji Coba Secara Luas (Main Field Test)}

Langkah-langkah uji coba produk secara luas meliputi: 1) melakukan uji efektifitas desain produk, 2) uji efektivitas desain, 3) hasil uji lapangan adalah desain yang efektif, baik sisi substansi maunpun metodologi.

\section{Revisi Hasil Uji Coba Secara Luas (Operational Product Revision)}

Langkah ini merupakan perbaikan kedua setelah diuji lapangan yang lebih luas dari uji lapangan yang pertama. Penyempurnaan produk dari hasil uji coba lapangan lebih luas ini akan memantapkan prtoduk yang akan kita kembangkan, karena pada tahap uji coba lapangan sebelumnya dilaksanakan dengan adanya kelompok kontrol.

\section{Produk akhir}

Setelah dilakukan uji coba produk secara luas maka tahap akhir dari pembuatan modul ini yaitu produk akhir dan modul bisa digunakan untuk proses belajar siswa.

\section{Instrumen Penelitian}

Instrument yang digunakan dalam penelitian ini berupa angket kelayakan modul untuk mendapatkan data hasil validasi dari 3 validator. Angket validasi bahasa terdiri dari 15 komponen pernyataan dengan skor 1-5. Angket validasi materi terdiri dari 16 komponen pernyataan dengan skor 1-5. Sedangkan Angket validasi media terdiri atas 16 komponen pernyataan dengan skor 1-5.

\section{Teknik Analisis Data}

Peneliti membuat lembar validasi yang berisikan pernyataan. Kemudian validator mengisi angket dengan memberikan tanda centang pada kategori yang telah disediakan oleh peneliti berdasarkan skala likert yang terdiri dari 5 skor penilaian sebagai berikut:

Tabel 1. Skor Penilaian Validasi Ahli

\begin{tabular}{cc}
\hline Keterangan & Skor \\
\hline Sangat Baik (SB) & 5 \\
Baik (B) & 4 \\
Cukup (C) & 3 \\
Kurang (K) & 2 \\
Sangat Kurang (SK) & 1 \\
\hline & (Sumber: Qoriah,2017)
\end{tabular}

Hasil validasi yang sudah tertera dalam lembar validasi modul akan dianalisis menggunkan rumus sebagai berikut:

Keterangan:

$$
\mathrm{P}=\frac{f}{N} \mathrm{X} 100 \%
$$

$\mathrm{P}=$ angka persentase data angket

$\mathrm{f}=$ jumlah skor yang diperoleh

$\mathrm{N}=$ jumlah skor maksimum

Selanjutnya persentase kelayakan yang didapatkan kemudian di interpretasikan ke dalam kategoti berdasarkan Tabel berikut: 
Tabel 2. Kreteria Kelayakan

\begin{tabular}{cc}
\hline Penilaian & Kreteria Interpretasi \\
\hline $81 \leq P \leq 100 \%$ & Sangat Layak \\
$61 \leq P<81 \%$ & Layak \\
$41 \leq P<61 \%$ & Cukup \\
$21 \leq P<41 \%$ & Tidak Layak \\
$0 \leq P<21 \%$ & Sangat Tidak Layak \\
\hline
\end{tabular}

Bahan ajar berbentuk modul dinyatakan layak secara teoritis apabila persentase kelayakan adalah $\geq 51 \%$.

\section{HASIL PENELITIAN DAN PEMBAHASAN}

Untuk melihat kelayakan modul, telah dilakukan validasi modul pada 3 dosen Institut Agama Islam Negeri Bengkulu. 1 dosen validasi bahasa, 1 dosen validasi materi, dan 1 dosen validasi media.

Sebelum menghitung persentase skor penilaian validasi ahli, akan dihitung terlebih dahulu kelayakan sesuai dengan rumus tabel 1.

Tabel 3. Data Hasil Validasi Ahli Bahasa

\begin{tabular}{llcr}
\hline No & Komponen & Skor & Kriteria \\
\hline 1 & Sesuai dengan perkembangan siswa & 8 & Sangat layak \\
2 & Komunikatif & 10 & Sangat layak \\
3 & Dialogis dan interaktif & 9 & Sangat layak \\
4 & Lugas & 8 & Sangat layak \\
5 & Koherensi dan keruntutan alur piker & 9 & Sangat layak \\
6 & Kesesuaian dengan kaidah bahasa & 9 & Sangat layak \\
& Indonesia yang baik dan benar & & \\
7 & Penggunaan istilah dan simbol/lambing & 13 & Sangat layak \\
& Jumlah total & & 66 \\
& Skor maksimal & & 75 \\
& Persentase & & $88 \%$ \\
& Kriteria & & Sangat layak \\
\hline
\end{tabular}

Tabel 4. Data Hasil Validasi Ahli Materi

\begin{tabular}{clcr}
\hline No & \multicolumn{1}{c}{ Komponen } & Skor & \multicolumn{1}{c}{ Kriteria } \\
\hline 1 & Materi & 14 & Sangat layak \\
2 & Kemutakhiran & 12 & Sangat layak \\
3 & Merangsang keingintahuan melalui & 12 & Sangat layak \\
& pendekatan Etnosains & & \\
4 & Mengembangkan kecakapan hidup & 12 & Sangat layak \\
5 & Mengembangkan wawasan kebhinekaan & 8 & Sangat layak \\
6 & Mengandung wawasan kontekstual & 4 & Sangat layak \\
& Jumlah total & & 62 \\
& Skor maksimal & & 80 \\
& Persentase & & $77,5 \%$ \\
& Kriteria & & Layak \\
\hline
\end{tabular}


Tabel 5. Data Hasil Validasi Ahli Materi

\begin{tabular}{clcr}
\hline No & \multicolumn{1}{c}{ Komponen } & Skor & \multicolumn{1}{c}{ Kriteria } \\
\hline 1 & Tampilan tulisan & 16 & Sangat layak \\
\hline 2 & Tampilan gambar & 20 & Sangat layak \\
\hline 3 & Fungsi modul & 18 & Sangat layak \\
\hline 4 & Manfaat modul & 16 & Sangat layak \\
\hline & Jumlah total & & 70 \\
\hline Skor maksimal & & 80 \\
\hline & Persentase & & Sangat layak \\
\hline & Kriteria & & \\
\hline
\end{tabular}

Berdasarkan hasil table 3, 4, dan 5 terlihat bahwa persentase pencapaian kriteria kelayakan untuk setiap komponen sudah berada pada kriteria sangat layak. Dari hasil validasi yang diperoleh dapat disimpulkan bahwa modul telah praktis untuk digunakan sebagai bahan ajar.

Namun demikian, untuk mendapatkan informasi lebih mendalam, pada angket juga diberikan ruang untuk menyampaikan komentar/kritik/saran pada catatan. Hal ini dimaksudkan agar validator lebih leluasa jika ingin menyampaikan pendapatnya. 3 dosen validator memberikan komentar positif yaitu modul sangat bagus untuk digunakan sebagai bahan ajar. Sementara itu berdasarkan saran yang diperoleh dari validator, ada beberapa revisi yang dilakukan yaitu memperbaiki tanda baca, menambahkan halaman francis, menambahkan sumber gambar pada modul, dan menambahkan isian siswa/peserta didik pada modul.

\section{KESIMPULAN DAN SARAN}

\section{Kesimpulan}

Dari hasil penelitian yang dilakukan, dapat disimpulkan bahwa modul pembelajaran IPA berbasis etnosains yang dikembangkan layak untuk digunakan dengan persentase $88 \%, 77,5 \%, 87,5 \%$ (kategori sangat layak, layak, dan sangat layak).

\section{Saran}

Berdasarkan hasil perolehan penelitian, maka penelitian dapat menyampaikan beberapa saran sebagai berikut:

1. Bagi siswa penelitian ini di harapkan sebagai salah satu sumber belajar berupa modul yang menggunakan pendekatan etnosains.

2. Bagi guru penelitian ini di harapkan dapat di jadikan acuan selanjutnya untuk lebih menekan pada pembelajaran berbasis etnosains.

3. Bagi peneliti lain dapat mencoba mengembangkan bahan ajar serupa pada materi yang berbeda sesuai kebutuhan.

4. Bagi peneliti agar membuat modul lanjutan untuk seluruh materi yang ada dikelas VII untuk SMP yang belum ada tercakup dalam modul. 


\section{DAFTAR PUSTAKA}

Anjarsari. (2014). Pembelajaran IPA Melalui InquiryBased Life-Cycle Thinking Project dala Mengembangkan Literasi Sains". Prosiding Seminar Nasional IPA V tahun 2014. "Scientific Learning dalam Konten dan Konteks Kurikulum 2013”. Hal 184192.

Atmojo, S.E. (2012). Profil Keterampilan Proses Sains dan Apresiasi Peserta didik Terhadap Profesi Pengrajin Tempe dalam Pembelajaran IPA Berbasis etnosains. Jurnal Pendidikan IPA Indonesia, 1(2): 115-122.

Arfinawati, S., Sudarmin, dan Sumarni, W.. (2016). Model Pembelajaran Kimia Berbasis Etnosains untuk Meningkatan Kemampuan Berpikir Kritis Siswa, Jurnal Pengajaran MIPA, No. 1, Vol. 21, 46-51.

Chiapetta, E.L. \& Koballa T. R. (2010). Science instruction in the middle and secondary school. Boston: Allyn \& Bacon.

Cristian, D., Rusilowati, A., dan Linuwih, S. (2017). Pengembangan Model Pembelajaran IPA Terintegrasi Etnosains untuk Meningkatkan Hasil Belajar dan Kemamuan Berpikir Kreatif, Journal of Innovative Science Education, No. 1, Vol.6, 116-128.

Damayanti, C., A. Rusilowati, \& S. Linuwih. (2017). Pengembangan Model Pembelajaran IPA Terintegrasi Etnosains untuk Meningkatkan Hasil Belajar dan Kemampuan Berpikir Kreatif. Journal of Innovative Science Education. 6(1): 117128.

Darmiatun. (2013). Menyusun Modul Bahan Ajar untuk Persiapan Guru dalam Mengajar Yogyakarta: Gava Media.

Emdin, C. (2011). Droppin' science and dropping science: African American males and urban science education. JAAME, 2(1) 1-15

Erman. (2014). Berdaya Saing dengan Literasi Sains. Prosiding Semnas Pensa VI "Peran Literasi Sains". Hal: 12-17.

Fokusindo Mandiri. (2012). Undang-undang SISDIKNAS (Sistem Pendidikan Nasional) Edisi Terbaru 2012. Bandung.

Hamalik, Oemar. (2011). Kurikulum dan Pembelajaran. Bandung: Bumi Aksara.

Kartono, Hairida, \& G. Bujang. (2010). Penelusuran Budaya Teknologi Lokal dalam Rangka Rekonstruksi dan Pengembangan Sains diSekolah Dasar. Pontianak: FKIP, Universitas Tanjungpura.

Kasa, I.W. (2011). Local Wisdom In Relation To Climate Change. Journal of International Society for Southeast Asian Agricultural Sciences (J.ISSAAS). 17(1): 22-27.

Kemendikbud. (2013). Permendikbud No.64 tentang Standar Isi Pendidikan Dasar dan Menengah. Jakarta: Kementrian Pendidikan dan Kebudayaan.

Krajcik, J.S., Czerniak, C.M, \& Berger, C. (1999). Teaching children science: A projectbased aprroach. Boston: McGraw Hill College.

Listyawati, M. (2012). Pengembangan Perangkat Pembelajaran IPA Terpadu di SMP. Jurnal Pendidikan IPA, 1(1): 61-69. 
Mukminan. (2014). Seminar Nasional Teknologi Pendidikan 2014 "Peningkatan Kualitas Pembelajaran Pendayagunaan Teknologi Pendidikan. Seminar Nasional Teknologi Pendidikan (pp. 1-11). Universitas Negeri Surabaya: Universitas Negeri Surabaya.

Novitasari, L., Agustina, P. A., Sukesti, R., Handhika, J., dan Nazri, M. F. (2017). Fisika, Etnosains dan Kearifan Lokal dalam Pembelajaran Sains. Prosiding SNPF (pp. 8182). Madiun: Universitas PGRI Madiun.

OECD. (2013). PISA 2012 Results in Focus What 15Year-Olds Know and What They Can Do with What They Know.

Ogawa, M. (2007). Toward a new rationale of science education in a non-western society, European Journal of Science Education, 8, 113-119.

Permanasari, Anna. (2011). Pembelajaran Sains: Wahana Potensial untuk Membelajarkan Softskill dan Karakter. Prosiding Seminar Nasional Pendidikan MIPA "Pengembangan Pembelajaran MIPA Berorientasi Soft Skill”. Hal: 20-30.

Purwanto, Budi. (2017). Arianto Nugroho, Eksplorasi Ilmu Alam,(Solo: PT. Tiga Serangkai pustaka Mandiri.

Qoriah, Y., Sumarno dan Umamah, N., (2017). The Development Prehistoric Of jember Of Thurism Module Using Dick And carey Model, Jurnal Historica, Vol.1, Issue.1

Rahayu, W. E. dan Sudarmin. (2015), Pengembangan Modul IPA Terpadu Berbasis Etnosains Tema Energi dalam Kehidupan untuk Menanamkan Jiwa Konservasi Siswa. Unnes Science Education Journal, No. 2, Vol. 4, 919-926.

Rahayu, U., Yumiati, Paulina Pannen. 2006. Instructional Quality Improvement in Science Though The Implementation Of Culture-Based Teaching Strateg, presented at the 10th International Conference Learning Together for Tomorrow: Education for Sustainable Develompemnt, Bangkok Thailand.

Rosyidah, A. N., Sudarmin., Siadi, Kusoro. (2013). Pengembangan Modul IPA Berbasis Etnosains Zat Aditif Dalam Bahan Makanan Untuk Kelas VIII SMPNegeri 1 Pegadon Kendal. Jurnal. Semarang : UnnesScience Education Journal. 2(1): 133139.

Sardjiyo \& Pannen, P. 2005 . Pembelajaran Berbasis Budaya: Model Inovasi Pembelajaran dan Implementasi Kurikulum Berbasis Kompetensi. Jurnal pendidikan, 6(2), 83-98.

Sayakti, L. (2003). Implementasi Konsep Lingkungan Hidup sebagai Sumber Belajar dalam Pembelajaran IPS di Sekolah Dasar. Tesis. SPs UPI, Bandung.

Setyosari, Punaji. (2013). Metode penelitian pendidikan dan pengembangan.(Jakarta: Prenadamedia.

Sibarani, R. (2013). Pendekatan Antropolinguistik dalam Menggali Kearifan Lokal Sebagai Identitas Bangsa. Prosiding The 5 International Conference on Indonesian Studies: "Ethnicity and Globalization". Yogyakarta: Universitas Indonesia.

Suastra I.W, \& Ketut, T. (2017). Efektifitas Model Pembelajaran Sains Berbasis Budaya Lokal untuk Mengembangkan Kompetensi Dasar Sains dan Nilai Kearifan Lokal di SMP. Jurnal Penelitian dan Pengembangan Pendidikan. 5(3): 258-271.

Syahid, A. 2018. Komponen Evaluasi Pembelajaran Bidang Studi Pendidikan Agama Islam dan Budi Pekerti. Jurnal Teknologi Pendidikan Madrasah 1(1): 33-52. 
Toharudin, U., \& Kurniawan I. S. (2017). Sundanese Cultural Values of Local Wisdom: Integrated to Develop a Model of Learning Biology. International Journal of Sciences: Basic and Applied Research (IJSBAR). 32(1): 29-49.

Ulfah, Maria. (2019). Efektivitas Rencana Pelaksanaan Pembelajaran (Rpp) Berbasis Etnosains Untuk Meningkatkan Minat dan Hasil Belajar Siswa Pada Materi Zat Aditif. E-jurnal Pensa. Volume 07 (01).

Widodo, Wahono dan Inzanah. (2014). "Model Pembelajaran Kimia Berbasis Etnosains (MPKBE) untuk Mengembangkan Literasi Sains Siswa". Prosiding Semnas Pensa VI "Peran Literasi Sains". Hal: 434-440.

Widodo, Wahono, dkk. (2016). Ilmu Pengetahuan Alam. Jakarta: Pusat Kurikulum dan Perbukuan.

Winarni, E. W. (2013). Perbandingan Sikap Peduli Lingkungan, Keterampilan Proses, dan Pemahaman Konsep Antara Siswa pada Pembelajaran IPA Menggunakan Pendekatan Jelajah Alam Sekitar (JAS) dan Ekspositori di Sekolah Dasar. Jurnal Ilmiah PGSD FIP UNJ, Vol. 5, No. 1, hlm. 145153.

Yasin, M. (2009). Implementasi Pembelajaran Sains Terpadu (Integrated Science Instruction) di SMP. Jurnal Pemikiran Alternatif Kependidikan. 14(1): 172-188.

Zuriyani, E. (2012). Literasi Sains dan Pendidikan. Diakses dari: http://www.sumsel.kemenag.go.id/file/file/TULISAN/wagj1343099486. (4 Januari 2017). 